\title{
Risk Factors for Piano-related Pain among College Students
}

\author{
Eri Yoshimura, M.M., Pamela Mia Paul, D.M.A., Cyriel Aerts, and Kris Chesky, Ph.D.
}

\begin{abstract}
Although pianists commonly report pain and musculoskeletal problems from playing, the related research literature on this topic is limited. The purpose of this study was to investigate the relationships between pain and several independent playing-related and anthropometric variables. Subjects included 35 piano majors attending a large college of music. Subjects were assessed with a questionnaire, bilateral anthropometric measurements of the upper arm and hand, and upper-extremity performance tests for range of motion, isometric strength, and rotation speed. Finger mobility, including active digit-to-digit span, was assessed using digital photography. Four questions regarding pain associated with piano were treated as dependent variables and used for correlation and regression analyses with other variables. A five-factor model emerged and each model was statistically significant. In addition to accounting for a large amount of variance associated with the dependent variables, results highlighted the importance of right 3-4 span (flexibility/mobility). This specific risk factor is rarely mentioned in the performing arts medicine literature. Additional studies are highly warranted for replication and for determining the clinical and pedagogical relevance of this finding. Med Probl Perform Art 2006; 21:118-125.
\end{abstract}

Q esearch in performing arts medicine suggests that 1 musicians experience pain and upper extremity musculoskeletal problems from playing the piano. ${ }^{1-8}$ Studies point to age as an important factor and indicate that females tend to report more problems than males. ${ }^{1-5}$ Hand size represents an important factor, and general anthropometric differences by gender may account for increased prevalence rates among females. ${ }^{4,9}$

Sakai ${ }^{3}$ has argued that technical demands, such as playing octaves, chords, and fortissimo, increase risk and are responsible for the majority of the hand and forearm problems. Wolf et al. ${ }^{10}$ also suggested that musculoskeletal problems are caused by playing loudly with high force and from using finger positions with high tendon and joint forces. Together, these studies imply that medical problems associated with piano performance involve a group of factors, including age, gender, hand size, technical requirements, biomechanical forces, and posture.

Ms. Yoshimura is a DMA student in piano performance with a related field of study in music and medicine; Dr. Paul is on the piano faculty; Mr. Aerts is a piano technician; and Dr. Chesky is director of the Texas Center for Music and Medicine (www.unt.edu/tcmm), University of North Texas, Denton, TX.

This study was supported by a UNT faculty research grant.

Address correspondence and reprint requests to: Eri Yoshimura, Texas Center for Music $\mathcal{E}$ Medicine, College of Music, University of North Texas, Avenue C, Denton, TX 76203. Tel 940-565-4126; fax 940-565-2002; email pianoeri@hotmail.com.
There are limitations associated with this literature, and additional investigations are warranted. Bragge ${ }^{11}$ indicated in his review of the literature that there are several methodologic limitations including statistical significance testing and that there is no consensus among authors regarding risk factors. Brandfonbrener ${ }^{12}$ highlighted the need for studies regarding individual physical variants and argued that arm segment lengths, hand widths, and finger lengths and proportions "are all-important considerations as risk factors."

The published information regarding joint mobility, especially lateral movements of fingers, remains inconclusive. De Smet ${ }^{4}$ reported that digit-to-digit span between the thumb and index finger is proportional to hand span and suggested a general correlation between these factors, whereas Wagner ${ }^{9}$ reported weak correlations for within-hand digit-to-digit span characteristics. The related literature remains unclear as to whether non-thumb digit-to-digit spans are correlated with hand span and, most importantly, whether they are correlated with pain associated with performing piano. The purpose of this study was to investigate risk factors for pianorelated pain among college students.

\section{METHODS}

\section{Subjects}

Following approval by the Institutional Review Board (IRB) of the University of North Texas, 35 piano performance majors at the university were recruited to participate in this study. Subjects were recruited through personal contact by the investigator, and they were compensated for their time.

\section{Procedure/Research Design}

The investigation included the following procedures. During the first meeting, the IRB consent form was presented to, reviewed, and signed by the subject. A questionnaire was administered. During a second meeting, extensive upper arm and hand anthropometric measurements were taken, along with a battery of bilateral upper-extremity performance tests for range of motion, isometric strength, and rotation speed.

\section{Questionnaire}

The questionnaire consisted of three sections: demographics and musical background, practice habits, and med- 
ical problems. The section on medical problems was divided into two subsections. The first subsection focused on pain associated with playing the piano as indicated in the following questions.

- Do you experience pain when playing?

- Do you experience pain after playing?

- Does pain stop you from playing the piano?

- How much of your playing is affected by your pain?

In this study, pain was conceptualized as one set of symptoms of a possible cluster of inter-related symptoms associated with playing-related musculoskeletal disorders (PRMD) as defined by Zaza et al. ${ }^{13}$ Each question was presented with a visual analogue scale (VAS) anchored with adjective descriptors representing the full range of possible responses (i.e., never to always). Subjects were instructed to mark responses along the $10-\mathrm{cm}$ line. The VAS is a reliable and valid approach for measuring pain. ${ }^{14-16}$ To determine the number of painful sites, subjects also were asked to mark the locations of pain on dorsal and palmer graphic representations of hands and on the front and back graphic representations of the torso.

The second subsection asked about general problems with nonmusculoskeletal issues, including problems with anxiety, stage fright, depression, fatigue, etc. Subjects marked either no problem, mild, or severe for each problem.

\section{Anthropometric Measurements}

A cloth measuring tape was used to take a series of bilateral upper extremity anthropometric measures, including upper

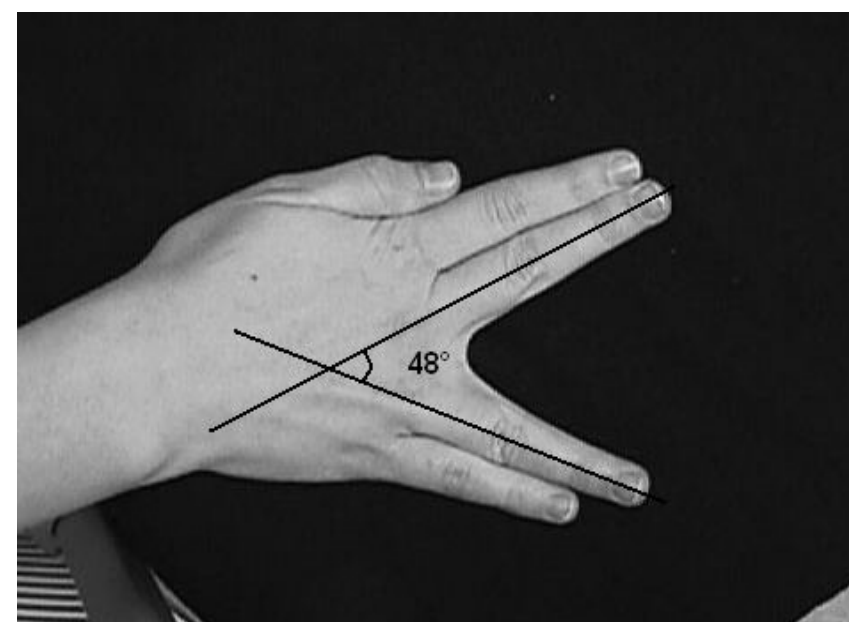

FIGURE 1. Maximum digit-to-digit span for digits 3-4 (right hand).

arm length (tip of the acromion to the lateral joint interspace of the elbow), forearm length (lateral joint interspace of the elbow to the lateral joint interspace of the wrist), hand length (dorsal joint interspace of the wrist to the tip of phalange 3), and wrist circumference (along the line connecting the most distal portions of the ulna and radius). Industry-standard jewelers' rings were used for measuring the circumference of digit 2 at the proximal interphalangeal (PIP) joint.

Hand volumes were measured using the displacement method, inserting each hand into a water volumeter up to the distal prominence of the ulna (ulnar head). Hand span was measured on a flat ruler by placing the tip of the thumb at the point 0 . Digit-to-digit span was measured using a digi-

TABLE 1: Demographic Characteristics and Music Background Data of Study Participants $(n=35)$

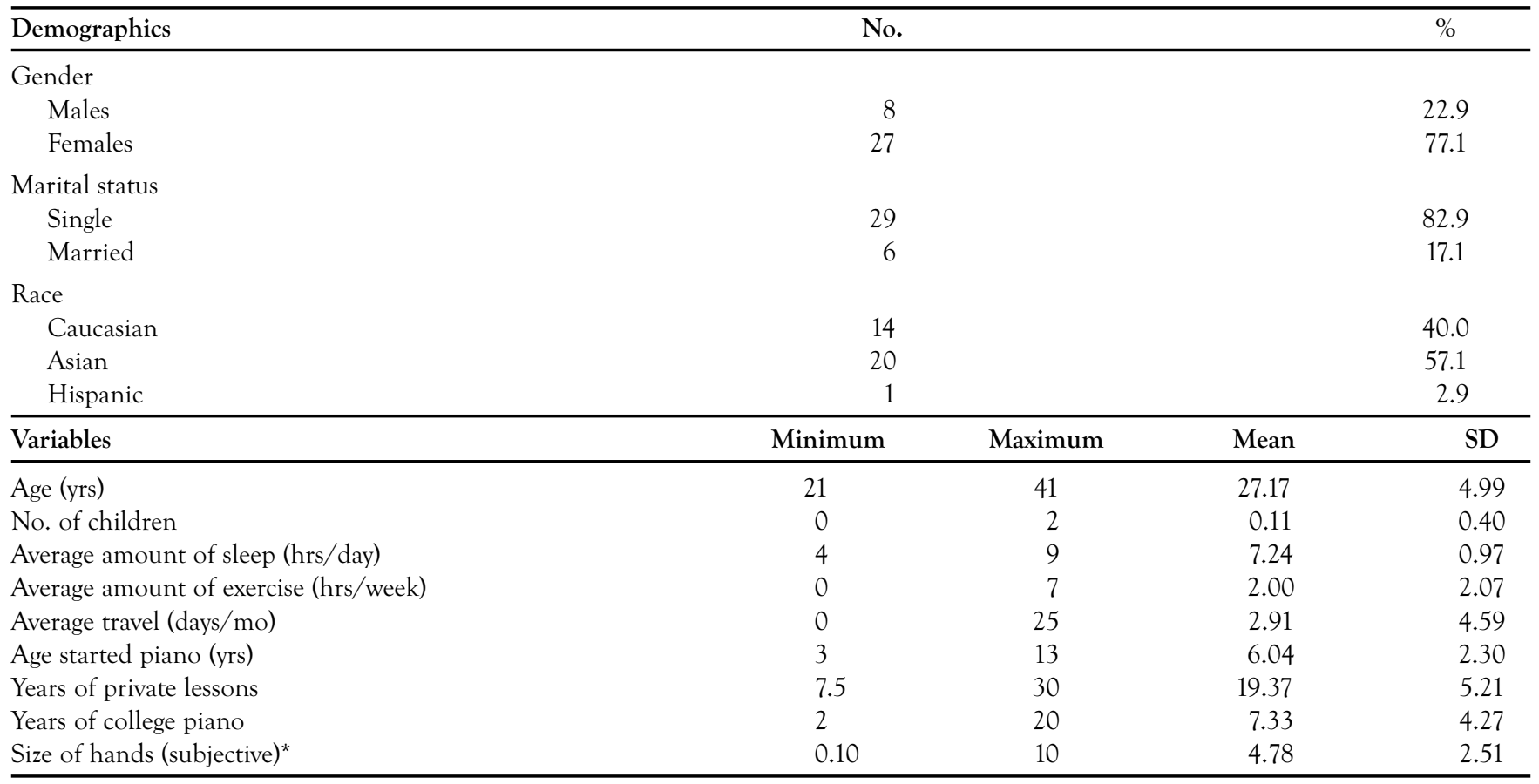

*Subjects answered on VAS $(0-10 \mathrm{~cm})$. 
TABLE 2: Practice Habits

\begin{tabular}{|c|c|c|c|c|}
\hline & Minimum & Maximum & Mean & SD \\
\hline Lesson hrs per wk & 0 & 6.0 & 1.20 & 0.96 \\
\hline Chamber music/ensemble hrs per wk & 0 & 6.0 & 1.11 & 1.62 \\
\hline Teaching hours per week & 0 & 25.0 & 5.49 & 7.45 \\
\hline Keyboard-related activities hrs per wk & 0 & 13.0 & 2.03 & 2.96 \\
\hline Practice hrs on upright piano per wk & 0 & 42.0 & 4.79 & 9.19 \\
\hline Practice hrs on grand piano per wk & 0 & 55.0 & 23.23 & 12.74 \\
\hline Do you warm-up before practice?* & 0 & 10.0 & 4.37 & 3.29 \\
\hline Physical warm-up time spent (min) & 0 & 60.0 & 3.26 & 10.46 \\
\hline Psychological warm-up time spent (min) & 0 & 60.0 & 2.03 & 10.23 \\
\hline Do you stop practice because of physical fatigue?* & 0 & 10.0 & 4.15 & 2.99 \\
\hline Do you stop practice because of mental fatigue?* & 0 & 10.0 & 5.46 & 3.11 \\
\hline Primary hand-related activities time spent (hrs/wk) & 0 & 19.0 & 3.67 & 3.99 \\
\hline
\end{tabular}

*Subjects answered on VAS $(0-10 \mathrm{~cm})$.

TABLE 3: Responses to Pain Questions and Nonmusculoskeletal Problems

\begin{tabular}{|c|c|c|c|c|}
\hline Pain Questions & Minimum & Maximum & Mean & SD \\
\hline Do you experience pain when playing? & 0 & 9.2 & 2.83 & 2.60 \\
\hline Do you experience pain after playing? & 0 & 9.0 & 2.91 & 2.79 \\
\hline How much of your playing is affected by pain? (\%) & 0 & 100.0 & 29.91 & 25.82 \\
\hline Nonmusculoskeletal Problems & $\begin{array}{l}\text { None } \\
n(\%)\end{array}$ & $\begin{array}{l}\text { Mild } \\
n(\%)\end{array}$ & & $\begin{array}{c}\text { Severe } \\
n(\%)\end{array}$ \\
\hline Acute anxiety & $27(77.1)$ & $8(22.9)$ & & $0(0)$ \\
\hline Asthma & $32(91.4)$ & $2(5.7)$ & & $1(2.9)$ \\
\hline Blackouts/dizziness & $32(91.4)$ & $3(8.6)$ & & $0(0)$ \\
\hline Chest discomfort & $31(88.6)$ & $4(11.4)$ & & $0(0)$ \\
\hline Chin rest sore & $34(97.1)$ & $1(2.9)$ & & $0(0)$ \\
\hline Depression & $23(65.7)$ & $12(34.3)$ & & $0(0)$ \\
\hline Headache & $21(60.0)$ & $13(37.1)$ & & $1(2.9)$ \\
\hline Hearing loss & $34(97.1)$ & $1(2.9)$ & & $0(0)$ \\
\hline Heart condition & $34(97.1)$ & $1(2.9)$ & & $0(0)$ \\
\hline Hemorrhoids & $35(100)$ & $0(0)$ & & $0(0)$ \\
\hline High blood pressure & $35(100)$ & $0(0)$ & & $0(0)$ \\
\hline Inguinal hernia & $35(100)$ & $0(0)$ & & $0(0)$ \\
\hline Loss of lip & $35(100)$ & $0(0)$ & & $0(0)$ \\
\hline Loss of seal & $35(100)$ & $0(0)$ & & $0(0)$ \\
\hline Mouth lesions & $34(97.1)$ & $1(2.9)$ & & $0(0)$ \\
\hline Respiratory allergies & $28(80.0)$ & $7(20.0)$ & & $0(0)$ \\
\hline Sleep disturbances & $27(77.1)$ & $8(22.9)$ & & $0(0)$ \\
\hline
\end{tabular}


TABLE 4: Number of Pain Sites and Nonmusculoskeletal Problems

\begin{tabular}{lrr}
\hline Total Sites/Problems & No. & $\%$ \\
\hline Pain Sites & & \\
0 & 3 & 8.6 \\
1 & 7 & 20.0 \\
2 & 4 & 11.4 \\
3 & 4 & 11.4 \\
4 & 9 & 25.7 \\
5 & 1 & 2.9 \\
6 & 1 & 2.9 \\
7 & 2 & 5.7 \\
8 & 2 & 5.7 \\
10 & 1 & 2.9 \\
14 & 1 & 2.9 \\
Total & 35 & 100.0 \\
Nonmusculoskeletal Problems & & \\
0 & 5 & 14.3 \\
1 & 7 & 20.0 \\
2 & 5 & 14.3 \\
3 & 2 & 5.7 \\
4 & 4 & 11.4 \\
5 & 3 & 8.6 \\
6 & 3 & 8.6 \\
7 & 2 & 5.7 \\
8 & 3 & 8.6 \\
11 & 1 & 2.9 \\
Total & 35 & 100.0 \\
\hline
\end{tabular}

tal photographic (Sony Digital Mavica MVC-FD7) representation of the performers' hands on a flat surface against a black cloth. Four photographs were taken for each hand to measure maximum active digit-to-digit span between thumb-index, 2-3, 3-4, and 4-5 digits. Span angles were measured on the printed photograph as shown in Figure 1.

\section{Elements of Performance}

Wrist range of motion, rotation speed, isometric strength, and pinch strength were measured bilaterally using the HPM Basic Elements of Performance XII System software and standardized protocol (Human Performance Measurement, Inc., Arlington, TX).

\section{Statistical and Analysis Methods}

All statistical analyses were done using SPSS software. The four pain questions from the questionnaire were treated as dependent variables (criterion variables) and the rest of the variables were treated as independent variables (predictor variables).

The following statistical procedures were followed: 1) descriptive statistics for questionnaire, anthropometric data, and elements of performance data; 2) cross-correlations between independent variables and dependent variables; 3 ) inter-correlations of independent variables significantly corre-

TABLE 5: Anthropometric Measures of Upper Extremity

\begin{tabular}{|c|c|c|c|c|}
\hline Variable & Minimum & Maximum & Mean & SD \\
\hline Height $(\mathrm{cm})$ & 147.0 & 188 & 164.09 & 9.81 \\
\hline Weight (kg) & 40.0 & 83 & 58.27 & 11.77 \\
\hline Left upper arm length (mm) & 260 & 350 & 298.74 & 22.18 \\
\hline Right upper arm length ( $\mathrm{mm})$ & 260 & 355 & 299.69 & 23.81 \\
\hline Left forearm length (mm) & 215 & 288 & 245.97 & 22.00 \\
\hline Right forearm length (mm) & 215 & 287 & 244.20 & 19.17 \\
\hline Left wrist circumference $(\mathrm{mm})$ & 135 & 181 & 153.77 & 12.40 \\
\hline Right wrist circumference (mm) & 140 & 184 & 154.23 & 12.95 \\
\hline Left index finger diameter $(\mathrm{mm})$ & 15.3 & 21 & 17.70 & 1.47 \\
\hline Right index finger diameter $(\mathrm{mm})$ & 15.9 & 21.3 & 17.98 & 1.46 \\
\hline Left hand volume $(\mathrm{mL})$ & 187.5 & 500 & 335.71 & 98.34 \\
\hline Right max. interval on keyboard & 8 & 11 & 9.57 & 0.74 \\
\hline $\mathrm{BMI}^{*}$ & 16.12 & 27.46 & 21.50 & 3.02 \\
\hline Left thumb-index span (deg) & 68 & 116 & 90.17 & 11.97 \\
\hline Right thumb-index span (deg) & 64 & 114 & 87.03 & 10.63 \\
\hline Left 2-3 span (deg) & 20 & 62 & 41.69 & 8.25 \\
\hline Right $2-3$ span (deg) & 17 & 54 & 39.17 & 8.03 \\
\hline Left 3-4 span (deg) & 18 & 50 & 31.63 & 7.06 \\
\hline Right 3-4 span (deg) & 10 & 48 & 29.69 & 8.40 \\
\hline Left 4-5 span (deg) & 32 & 65 & 48.20 & 8.31 \\
\hline Right $4-5$ span (deg) & 18 & 64 & 45.49 & 8.59 \\
\hline
\end{tabular}

${ }^{*}$ Body mass index, $\mathrm{BMI}=$ weight in $\mathrm{kg} /(\text { height in } \mathrm{cm})^{2} \times 10,000$. 
TABLE 6: Basic Elements of Performance

\begin{tabular}{|c|c|c|c|c|}
\hline Variables & Minimum & Maximum & Mean & SD \\
\hline Range of motion left pronation (deg) & 61.7 & 153.9 & 101.28 & 20.21 \\
\hline Range of motion left supination (deg) & 60.1 & 177.1 & 123.65 & 24.81 \\
\hline Range of motion right supination (deg) & 92.9 & 175.8 & 131.87 & 22.90 \\
\hline Rotation speed left pronation $(\mathrm{deg} / \mathrm{sec})$ & 331.0 & 1703.0 & 690.56 & 312.89 \\
\hline Rotation speed left supination (deg/sec) & 277.5 & 1521.0 & 889.16 & 306.73 \\
\hline Isometric strength left pronation $(\mathrm{N}-\mathrm{m})$ & 2.3 & 21.1 & 6.53 & 3.70 \\
\hline Isometric strength left supination $(\mathrm{N}-\mathrm{m})$ & 2.1 & 10.8 & 4.09 & 2.25 \\
\hline Isometric strength right pronation $(\mathrm{N}-\mathrm{m})$ & 2.3 & 19.3 & 6.02 & 3.81 \\
\hline Isometric strength right supination $(\mathrm{N}-\mathrm{m})$ & 2.4 & 13.0 & 6.45 & 2.28 \\
\hline Pinch strength left $(\mathrm{N})$ & 1.2 & 2.8 & 2.01 & 0.39 \\
\hline Right & 33 & & 94.3 & \\
\hline Left & 1 & & 2.9 & \\
\hline \multicolumn{5}{|l|}{ Hyperlaxity } \\
\hline Yes & 6 & & 17.1 & \\
\hline No & 29 & & 82.9 & \\
\hline
\end{tabular}

lated with one or more dependent variable(s); 4) factor development for regression modeling by grouping together independent variables based on cross and inter-correlations with dependent variables; and 5) regression (Enter method) analysis for each dependent variable using one independent variable (highest correlation with dependent variable) from each factor.

\section{RESULTS}

\section{Descriptive Analyses}

The study participants ranged in age from 21 to 41 yrs (average, $27 \mathrm{yrs}$ ) and included 8 males (23\%) and 27 females (77\%). As shown in Table 1, the age at starting piano-playing ranged from 3 to 13 years. Over $50 \%$ of subjects reported Asian ethnicity.

Subjects reported an average of $24 \mathrm{hrs} /$ week of practice time (Table 2). On average, subjects reported five school performances per semester and over 5 hrs of teaching per week.

Table 3 shows the responses to the four pain questions and responses to the nonmusculoskeletal problems. Eightysix percent of subjects answered that they experienced pain when playing.

Nine subjects (25.7\%) reported that they had musculoskeletal pain in four locations (Table 4). For nonmusculoskeletal problems, $20 \%$ of subjects answered that they had one problem.

The active digit-to-digit span data, shown in Table 5 , indicates that the average left-hand span was larger than the right-hand span. Another tendency was that right-side anthropometric characteristics were generally larger than the left side, except for span and forearm length.
Almost $83 \%$ of subjects showed no signs of hyperlaxity (Table 6). The means of range of motion and rotation speed were greater for supination than for pronation. Left supination represented the weakest isometric strength measure.

\section{Cross- and Inter-correlations}

Cross-correlations with independent variables showed many significant correlations with the four pain questions, as shown in Table 7. In general, anthropometric measurements were inversely correlated with the dependent variables.

Based on inter-correlations, variables were categorized into five groups (factors): 1) age/exposure, 2) size/strength/ speed, 3) flexibility, 4) number of nonmusculoskeletal problems, and 5) number of musculoskeletal problems. Size, strength, and speed were significantly correlated and categorized into one factor. Hand span and range of motion were similarly treated, as shown in Table 8.

\section{Factor Identification}

Factor identification for regression modeling resulted in a five factor set of independent variables for each of the four dependent variables. As shown in Table 9, the variable selected for each model to best represent the individual factors was not the same for each model. Conditions for choosing independent variables included 1) the highest correlations with each dependent variable, and 2) if this independent variable was significantly correlated with other variables selected for the model, the next or second highest correlated variable (indicated as *) was selected. 
TABLE 7: Variables Correlated with One or More Dependent Variables

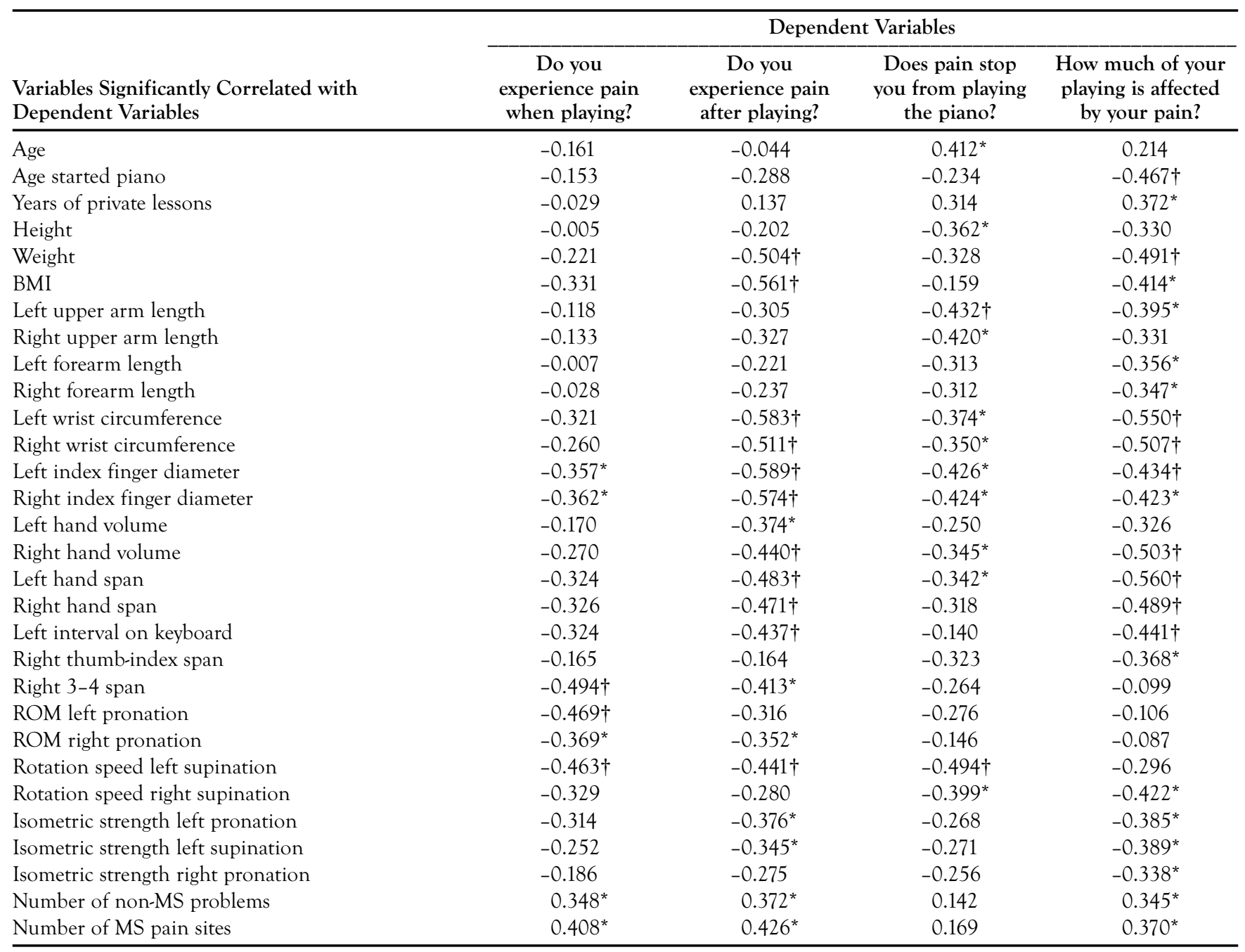

${ }^{*}$ Correlation is significant at the 0.05 level (2-tailed).

$\dagger$ Correlation is significant at the 0.01 level (2-tailed).

\section{Regression Analysis}

As shown in Table 10, results from the regression analysis showed that each model was statistically significant $(p<$ 0.0005 for models 1,2 , and 4 and $p<0.005$ for model 3 ). The adjusted $R^{2}$ showed that variance accounted for ranged from $40 \%$ for model 3 to $60 \%$ for model 2 .

For models 1 and 2 , the $\beta$ weight for factor 3 , based on the right-hand 3-4 digit span variable, was the most or second strongest factor. As a follow-up analysis, the variable (right 3-4 span) was excluded from and then added to the regression model in order to observe the change of adjusted $R^{2}$. For model 1 , the adjusted $R^{2}$ was increased from 0.361 to 0.549 by adding the right $3-4$ span variable, and from 0.389 to 0.602 for model 2 .

\section{DISCUSSION AND CONCLUSIONS}

This study used a statistical approach to investigate risk factors for piano-related pain. Knowledge of these factors is needed to help understand why piano players report pain. Such information can be applied toward the development of effective preventative strategies and clinical responses to pain.

Results show that finger joint mobility, particularly right 3-4 span, is a risk factor for piano-related playing. This is an important finding because it has not been noted in previous studies. Consistent with reports for $\mathrm{Pak}^{1}$ and De Smet, ${ }^{4}$ this study also showed that age and size are important risk factors for pain. In this study, however, age was conceptualized as a factor or set of related variables due to significant inter-correlations. Similarly, size, strength, and speed were grouped into one factor. The data from this study indicated that time, or number of years, playing the piano is positively associated with problems. The negative association with size/strength/ speed suggests that the piano players with smaller hands are at increased risk for problems. A positive association between factor 4 (number of nonmusculoskeletal problems) and the dependent variables suggests that a possible "overall health" factor may be involved. 
TABLE 8: Five Factors with Related Variables

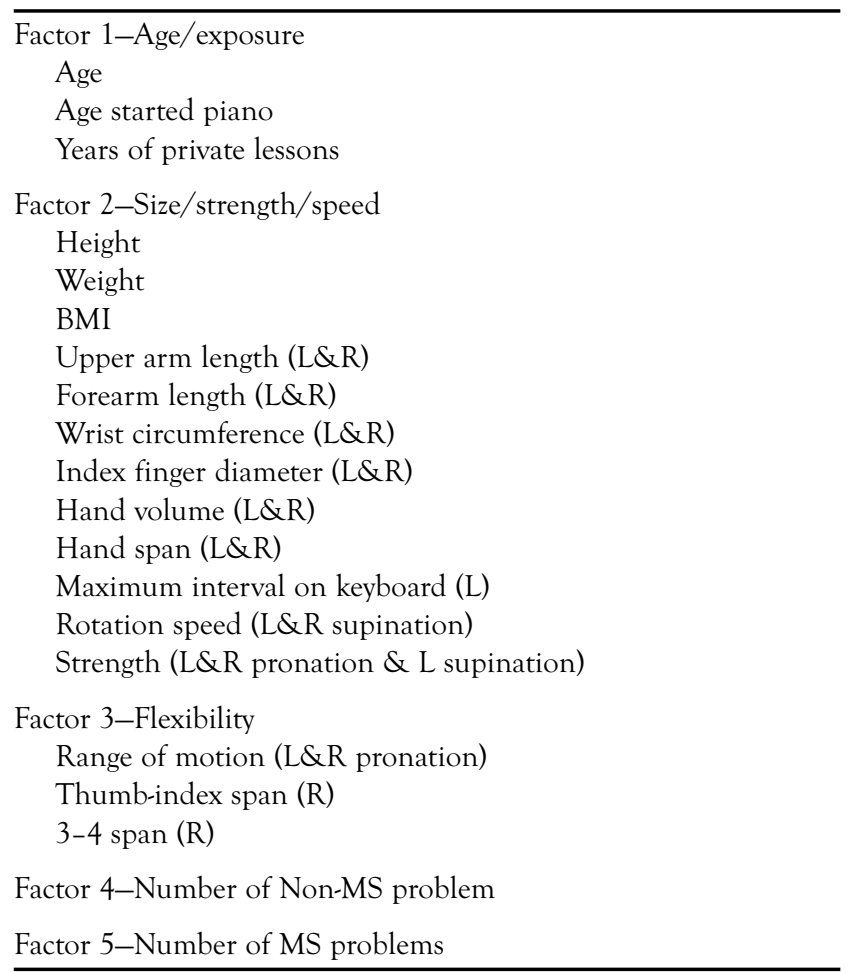

Together, as shown in model 2, five statistically independent factors accounted for about $60 \%$ of the variance in the dependent variable (adjusted $R^{2}=0.602$ ). Even though this study documents the apparent importance of right 3-4 span as a strong contributor to the overall variance associated with pain among pianists, $40 \%$ of the variance remains unaccounted for. As highlighted by Sakai, 3,5 biomechanical force and performance technique (octave and chords) are important factors to consider. Other factors, such as genetics and nutrition, also may be important to general and specific levels of vulnerability and susceptibility.
Because of the relevance associated with the right 3-4 span variable, this study needs to be replicated with larger and more diverse populations. The limitations associated with this study, including the small sample size and generally homogeneous level of performance ability among subjects pursuing a degree in piano performance, restrict generalizations from these findings.

Nevertheless, this study raises important questions for the field of performing arts medicine. Primarily, what are the developmental, pedagogical, and clinical implications for piano players with limited right 3-4 span? Considering that lateral movements of digits involve the metacarpophalangeal joint and extensor communis tendons, and that there are three distinct morphologic types of juncturae tendinum, ${ }^{17}$ does pain implicate possible anatomical variants in the juncturae tendinum?

\section{ACKNOWLEDGMENT}

The authors thank Dr. Craig Neumann for his consultation and review of the statistical procedures used in this study.

\section{REFERENCES}

1. Pak $\mathrm{CH}$, Chesky KS: Prevalence of hand, finger, and wrist musculoskeletal problems in keyboard instrumentalists. Med Probl Perform Art 2000; 15:17-23.

2. Revak JM: Incidence of upper extremity discomfort among piano students. Am J Occup Ther 1989; 43:149-154.

3. Sakai N: Hand pain related to keyboard techniques in pianists. Med Probl Perform Art 1992; 7:63-65.

4. De Smet L, Ghyselen H, Lysens R: Incidence of overuse syndromes of the upper limb in young pianists and its correlation with hand size, hypermobility and playing habits. Ann Chir Main 1998; 17:309-313.

5. Sakai N: Hand pain attributed to overuse among professional pianists: a study of 200 cases. Med Probl Perform Art 2002; 17:178-180.

6. Grieco A, Occhipinti E, Colombini D, et al: Muscular effort and musculoskeletal disorders in piano students: electromyographic, clinical and preventive aspects. Ergonomics 1989; 32:697-716.

7. Blackie H, Stone R, Tiernan AM: An investigation of injury prevention among university piano students. Med Probl Perform Art 1999; $14: 141-149$

TABLE 9: Regression Model

\begin{tabular}{|c|c|c|c|c|}
\hline & $\begin{array}{c}\text { Model } 1 \\
\text { Do you } \\
\text { experience pain } \\
\text { when playing? }\end{array}$ & $\begin{array}{c}\text { Model } 2 \\
\text { Do you } \\
\text { experience pain } \\
\text { after playing? }\end{array}$ & $\begin{array}{c}\text { Model } 3 \\
\text { Does pain stop } \\
\text { you from } \\
\text { playing the piano? }\end{array}$ & $\begin{array}{c}\text { Model } 4 \\
\text { How much of your } \\
\text { playing is affected } \\
\text { by your pain? }\end{array}$ \\
\hline Factor 1 (Age / exposure) & Age & $\begin{array}{l}\text { Years of college piano } \\
\text { instruction* }\end{array}$ & Age & Years of private lessons* \\
\hline Factor 2 (Size/strength/speed) & $\begin{array}{l}\text { Rotation speed left } \\
\text { supination }\end{array}$ & $\begin{array}{l}\text { Left index finger } \\
\text { diameter }\end{array}$ & $\begin{array}{l}\text { Rotation speed } \\
\text { left supination }\end{array}$ & Left hand span \\
\hline Factor 3 (Flexibility) & Right 3-4 span & Right 3-4 span & $\begin{array}{l}\text { Right thumb-index } \\
\text { span }\end{array}$ & $\begin{array}{l}\text { Right thumb-index } \\
\text { span }\end{array}$ \\
\hline Factor 4 (Non-MS problems) & $\begin{array}{l}\text { Number of non-MS } \\
\text { problems }\end{array}$ & $\begin{array}{l}\text { Number of non-MS } \\
\text { problems }\end{array}$ & $\begin{array}{l}\text { Number of non-MS } \\
\text { problems }\end{array}$ & $\begin{array}{l}\text { Number of non-MS } \\
\text { problems }\end{array}$ \\
\hline Factor 5 (MS problems) & $\begin{array}{c}\text { Number of MS } \\
\text { location }\end{array}$ & $\begin{array}{c}\text { Number of MS } \\
\text { location }\end{array}$ & $\begin{array}{c}\text { Number of MS } \\
\text { location }\end{array}$ & $\begin{array}{c}\text { Number of MS } \\
\text { location }\end{array}$ \\
\hline
\end{tabular}

*Second highest correlated variable. 
TABLE 10: Regression Data

\begin{tabular}{|c|c|c|c|c|c|}
\hline & Predictors & Beta & Adjusted $R^{2}$ & $F$ & $p$-Value \\
\hline Factor 1 & Age & -0.205 & & & \\
\hline Factor 3 & Right 3-4 span & -0.430 & & & \\
\hline Factor 4 & Number of non-MS problems & 0.184 & & & \\
\hline Factor 5 & Number of MS problems & 0.263 & & & \\
\hline Factor 1 & Years of college piano instruction & -0.165 & & & \\
\hline Factor 2 & Left index finger diameter & -0.540 & & & \\
\hline Factor 3 & Right 3-4 span & -0.468 & & & \\
\hline Factor 4 & Number of non-MS problems & 0.167 & & & \\
\hline Factor 5 & Number of MS problems & 0.175 & & & \\
\hline Factor 4 & Number of non-MS problems & 0.203 & & & \\
\hline Factor 5 & Number of MS problems & 0.074 & & & \\
\hline Model 4 & & & 0.447 & 6.500 & 0.000 \\
\hline Factor 1 & Years of private lessons & 0.259 & & & \\
\hline Factor 2 & Left hand span & -0.368 & & & \\
\hline Factor 3 & Right thumb-index span & -0.164 & & & \\
\hline Factor 4 & Number of non-MS problems & 0.227 & & & \\
\hline Factor 5 & Number of MS problems & 0.235 & & & \\
\hline
\end{tabular}

8. Shields N, Dockrell S: The prevalence of injuries among pianists in music schools in Ireland. Med Probl Perform Art 2000; 15:155-159.

9. Wagner $\mathrm{CH}$ : The pianist's hand: anthropometry and biomechanics. Ergonomics 1988; 31:97-131.

10. Wolf FG, Keane MS, Brandt KD, Hillberry BM: An investigation of finger joint and tendon forces in experienced pianists. Med Probl Perform Art 1993; 8:84-95.

11. Bragge P, Bialocerkowski A, McMeeken J: A systematic review of prevalence and risk factors associated with playing-related musculoskeletal disorders in pianists. Occup Med 2006; 56:18-27.

12. Brandfonbrener AG: Epidemiology and risk factors. In Tubiana R, Adadio P (eds): Medical Problems of the Instrumental Musician.
London, Martin Dunitz, 2000.

13. Zaza C, Charles C, Muszynski A: The meaning of playing-related musculoskeletal disorders to classical musicians. Soc Sci Med 1998; 47:2013-2023.

14. Katz J, Melzack R: Measurement of pain. Surg Clin North Am 1999; 79:231-252.

15. Scott J, Huskisson EC: Graphic representation of pain. Pain 1976; 2:185-195.

16. Carlsson AM: Assessment of chronic pain: I. Aspects of the reliability and validity of the visual analogue scale. Pain 1983; 16:87-101.

17. von Schroeder HP, Botte MJ, Gellman H: Anatomy of the juncturae tendinum of the hand. J Hand Surg 1990; 15:595-602. 